\title{
Apoptotic Properties of Rutheinum Complexes on Different Type of Cancer Cell Lines ${ }^{\dagger}$
}

\author{
Hafize Seda Vatansever 1,2, , Hilal Kabaday1 ${ }^{1}$, Mehmet Korkmaz ${ }^{3}$, Feyzan Özdal-Kurt 4,5, \\ Serdar Batıkan Kavukcu ${ }^{6}$ and Hayati Türkmen ${ }^{6}$ \\ 1 Faculty of Medicine, Department of Histology and Embryology, Manisa Celal Bayar University, \\ Manisa 45020, Turkey; kabadayihilal@gmail.com \\ 2 Experimental Health Research Center of Health Sciences, Near East University, Mersin-10, Cyprus \\ 3 Faculty of Medicine, Department of Medical Biology, Manisa Celal Bayar University, Manisa 45020, \\ Turkey; korkmaz1@yahoo.com \\ 4 Faculty of Sciences and Letters, Department of Biology, Manisa Celal Bayar University, Manisa 45020, \\ Turkey; feyzanozdalkurt@yahoo.com \\ 5 Department of Molecular, Cell and Systems Biology, Stem Cell Center, College of Natural and Agricultural \\ Sciences, University of California Riverside, Riverside, CA 95521, USA \\ 6 Faculty of Science, Department of Chemistry, Ege University, Izmir 35040, Turkey; \\ sbkavukcu@gmail.com (S.B.K.); hayati.turkmen@ege.edu.tr (H.T.) \\ * Correspondence: seda.vatansever@cbu.edu.tr; Tel.: +90-236-233-8586 \\ + Presented at the 2nd International Cell Death Research Congress, Izmir, Turkey, 1-4 November 2018. \\ Published: 11 December 2018
}

\begin{abstract}
Among chemotherapeutic agents, cisplatin and the other platinum-based drugs have occupied for 35 years an enviable position. The limitations of platinum-based drugs, dose dependent side effects and development of drug resistance mechanisms, have boosted the research for finding other metal-based drugs. Among metals, ruthenium is probably the one showing the greatest promises. Ruthenium (Ru) appears to be less toxic than platinum and several biological studies have indicated that ruthenium complexes possess diverse modes of action. The redox chemistry of ruthenium is rich and compatible with biological media, and the overall toxicity of ruthenium is lower than platinum, thus allowing higher doses of treatment. In this study we aimed that, analyses of different type of ruthenium complexes in cancer cell lines. Six Ru complexes were determined by elemental analysis, FTIR, NMR, UV-visible spectroscopy, electron density on the metal was measured by cyclic voltammetry. After that, the cellular properties of this complexes were analyses on PC-3, HT-29, Du-145 and Vero cell lines. DNA damage was analyzed H2AX staining, apoptotic cell analyses were performed flow cytometry and western blotting. After $48 \mathrm{~h}$ incubation of $\mathrm{Ru}$ complexes three of them more effective for cell lines. Especially Ru3 was more effective in cancer cell lines. Apoptotic pathway was triggered after Ru complexes incubation in PC3, Du-145 and Ht-29 cancer cell lines. Our study suggest that Ru complexes may be used for cancer cell cytotoxicity as a drugs in patients.
\end{abstract}

Keywords: ruthenium; anticancer effects; cell death

\section{Introduction}

Several metal complexes such as platin, ruthenium, rhodium, iridium and palladium have been investigated for cancer treatment since 1965. The limitations of platinum-based drugs, dose dependent side effects and development of drug resistance mechanisms, have boosted the research for finding other metal-based drugs [1]. Ruthenium-based compounds have received great interest due to their potent cytotoxic activity in cancer cells [2-4]. Ruthenium appears to be less toxic than platinum and several biological studies have indicated that ruthenium complexes possess diverse 
modes of action [2]. The redox chemistry of ruthenium is rich and compatible with biological media, and the overall toxicity of ruthenium is lower than platinum, thus allowing higher doses of treatment. In addition, rhodium(III) and iridium(III) complexes (isoelectronic to ruthenium(II)) have also been identified as biologically relevant metals, and their complexes are gaining attention as alternatives to platinum-containing compounds [5-8]. Mono- and polynuclear ruthenium-arene and pentamethylcyclopentadienyl rhodium and iridium complexes have demonstrated promising pharmacological activities, making them viable candidates for further biological study. In addition, apoptotic properties of ruthenium complexes compound still unclear. The apoptotic properties of three Ru complexes were investigated on PC3, Vero, Du145, and HT29 cancer cell lines.

\section{Materials and Methods}

Complex Ru:C $\mathrm{C}_{1}(1.00 \mathrm{~g}, 4.13 \mathrm{mmol})$ and $\left[\mathrm{RuCl}_{2}(p-c y m e n e)\right]_{2}(1.26 \mathrm{~g}, 2.06 \mathrm{mmol})$ were dissolved in $20 \mathrm{~mL}$ dry $\mathrm{MeCN}$. The mixture was refluxed overnight. The oil bath was removed. $\mathrm{NH}_{4} \mathrm{PF}_{6}(0.67$ $\mathrm{g}$, $4.13 \mathrm{mmol}, 1$ eq.) was dissolved with $\mathrm{MeCN}$ and added the mixture. The mixture was filtered. The filtrate was evaporated to dryness. The complex was obtained by column chromatography from DCM. PC3 (prostate adenocarcinoma, CRL1435, ATCC), Vero (kidney cells, CCL-81, ATCC), Du145 (prostate carcinoma, HTB-81, ATCC) and HT29 (colon adenocarcinoma, HTB-38, ATCC) cancer cell lines were cultured in DMEM (F0415, Biochrom, Berlin, Germany) supplemented with 10\% fetal bovine serum (FBS, HI-12B Capricorn Scientific, Ebsdorfergrund, Germany), 1\% penicillinstreptomycine (15140122 Gibco $^{\mathrm{TM}}$, Waltham, MA, USA) and 1\% L-glutamine (A2916801, Gibco ${ }^{\mathrm{TM}}$, Waltham, MA, USA). DNA damage was demonstrated distribution of H2AX (NB100-383, Novus Biol, Littleton, CO, USA) using indirect immunohistochemistry. For Western blot analysis, primary antibodies [anti-p53 (NB200-103), anti-cytochrome C (NB100-56503, Novus Biol, Littleton, CO, USA), anti-PARP (NBP2-36747, Novus Biol, Littleton, CO, USA), anti-Bcl-2 (NB100-56098, Novus Biol, Littleton, CO, USA), Anti-Bcl-xL (NB100-56105), anti-Bax (NBP1-28566), anti-p53 (PSer15NB1001913), anti- $\beta$-Aktin (NB600-501, Novus Biol, Littleton, CO, USA)] were analyzed. Analysis of apoptotic cells was performed by flow cytometry (BD Accuri C6 plus) after $48 \mathrm{~h}$ incubation with Ru complexes. Briefly, cells were incubated with Annexin V-FITC (MedSystems Diagnostics, Vienna, Austria) and propidium iodide (Sigma, St. Louis, MO, USA) or caspase 3/7 (556485, BD, Franklin Lakes, NJ, USA) in a binding buffer for $10 \mathrm{~min}$ at room temperature, washed and resuspended in the same buffer.

\section{Results}

Three ruthenium complexes containing ethylenediamine were synthesized according to published procedures. To compare with the complexes $\left(\mathbf{R} \mathbf{u}_{2-3}\right)$, the complex $\mathbf{R} \mathbf{u}_{1}$ which is analogue of $\mathbf{R} \mathbf{u}_{1}$ was synthesized. All complexes (Ru1-3) were stable with $\mathrm{PF}_{6}$ anions. Although, the solubility of complex $\mathbf{R} \mathbf{u}_{1}$ was very well in polar and apolar solvents, $\mathbf{R} \mathbf{u}_{2-3}$ were well in polar solvents. The pianostool complexes were air- and moisture-stable orange solids. The complexes ( $\left.\mathbf{R u}_{1-3}\right)$ were characterized by ${ }^{1} \mathrm{H},{ }^{13} \mathrm{C},{ }^{19} \mathrm{~F}$ and ${ }^{31} \mathrm{P}$ NMR spectroscopy, elemental analysis and cyclic voltammetry. Single crystals for the solid-state structures were obtained by diffusion of dietylether into concentrated solutions of the complexes in dichloromethane. The molecular structures of complex $\left(\mathbf{R} \mathbf{u}_{2}\right)$ were determined by single-crystal X-ray diffraction. The complex exhibit piano-stool type geometry. Using inverted microscopy to analyze cell morphology, we observed cell shrinkage, chromatin condensation and nuclear fragmentation in DU145, HT29, PC3 and Vero cells treated with $\mathbf{R} \mathbf{u}_{3}$ (Figure 1). Incubation with $\mathbf{R} \mathbf{u}_{1}$ and $\mathbf{R} \mathbf{u}_{2}$ cell morphologies were similar with control group (Figure 1). H2AX staining was weak and moderate on PC3 cells after $\mathbf{R} \mathbf{u}_{1}, \mathbf{R} \mathbf{u}_{2}$ and $\mathbf{R} \mathbf{u}_{3}$ incubation, respectively. In Vero cells, H2AX immunoreactivity was weak after $\mathbf{R} \mathbf{u}_{1}$ incubation, in addition moderate and strong immunoreactivities were detected $\mathbf{R} \mathbf{u}_{1}$ and $\mathbf{R} \mathbf{u}_{2}$ incubations, respectively. After three type of $\mathbf{R} \mathbf{u}$ incubation, moderate H2AX immunoreactivity was observed on DU145 cells. HT29 cells was strong or moderate staining of H2AX were detected after incubation with $\mathbf{R} \mathbf{u}_{1}, \mathbf{R} \mathbf{u}_{2}$ and $\mathbf{R} \mathbf{u}_{3}$ incubation, respectively (Figure 2). Using flow cytometry after a $48 \mathrm{~h}$ of incubation, incubation with $\mathbf{R} \mathbf{u}_{2}$ for Vero and HT-29 cells, with $\mathbf{R} \mathbf{u}_{3}$ Du-145 cells apoptotic cell 
numbers were increased (Figure 3). In PC3 cells, there was no difference after incubation with Ru complexes. While caspase 3/7 distribution was increased in Vero and HT-29 cells after Ruz and in Du-145 cells after Ru3 incubations (Figure 3). Western blot analyses showed that cytochrome-C expression was less when compared other apoptotic markers in all cell types control groups, however, increased cytochrome expression was detected in all cell types after $\mathbf{R u}$ complexes incubation. $R \mathbf{u}_{3}$ incubation was more dramatically effected this expression in all cell types. increased after $\mathbf{R} \mathbf{u}_{3}$ incubation. Caspase-3 expression was also decreased after three type of $\mathbf{R} \mathbf{u}$ complexes incubation, $\mathbf{R} \mathbf{u}_{3}$ was also more effective than others. Caspase- 3 expression was negative in HT-29 cells, this expression was increased after $\mathbf{R u}$ complexes incubation.
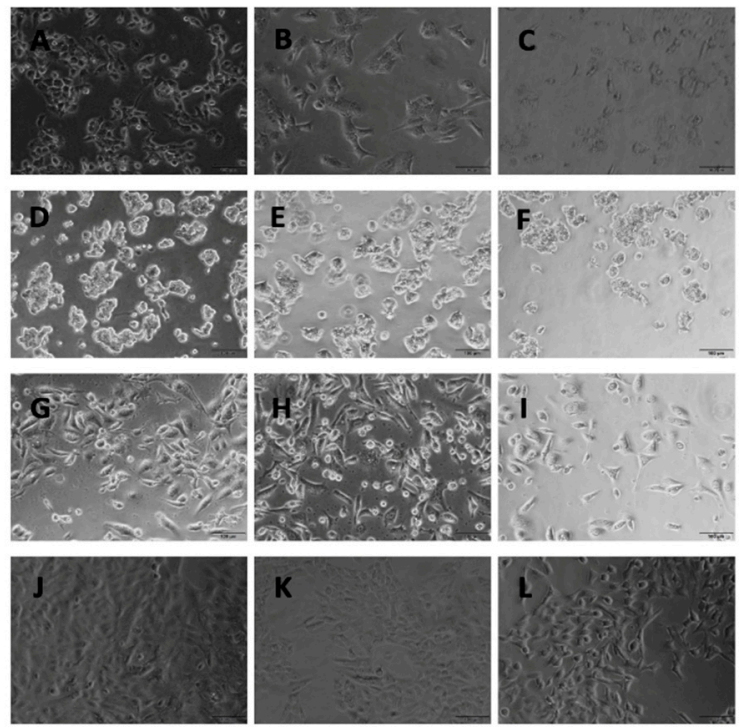

Figure 1. Incubation of $\mathbf{R} \mathbf{u}_{1}(\mathbf{A}, \mathbf{D}, \mathrm{G}, \mathbf{J}), \mathbf{R} \mathbf{u}_{2}(\mathbf{B}, \mathbf{E}, \mathbf{H}, \mathbf{K}), \mathbf{R} \mathbf{u}_{3}(\mathbf{C}, \mathbf{F}, \mathbf{I}, \mathrm{L})$ compounds for 48 h on DU145 (AC), HT29 (D-F), PC31 (G-I) and Vero (J-L) cells. Scale Bars: $100 \mu \mathrm{m}$.

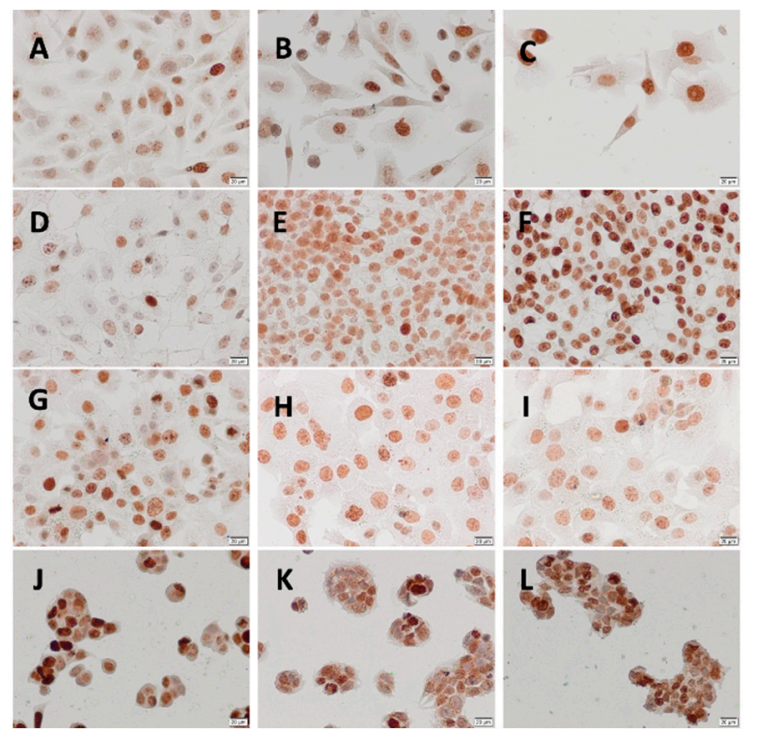

Figure 2. H2AX staining on PC3 (A-C), Vero (D-F), DU145 (G-I) and HT29 (J-L) after $48 \mathrm{~h}$ incubation with $\mathbf{R} \mathbf{u}_{1}(\mathbf{A}, \mathbf{D}, \mathbf{G}, \mathbf{J}), \mathbf{R u}_{2}(\mathbf{B}, \mathbf{E}, \mathbf{H}, \mathbf{K}), \mathbf{R} \mathbf{u}_{3}(\mathbf{C}, \mathbf{F}, \mathbf{I}, \mathbf{L})$ compounds Scale Bars: $20 \mu \mathrm{m}$. 


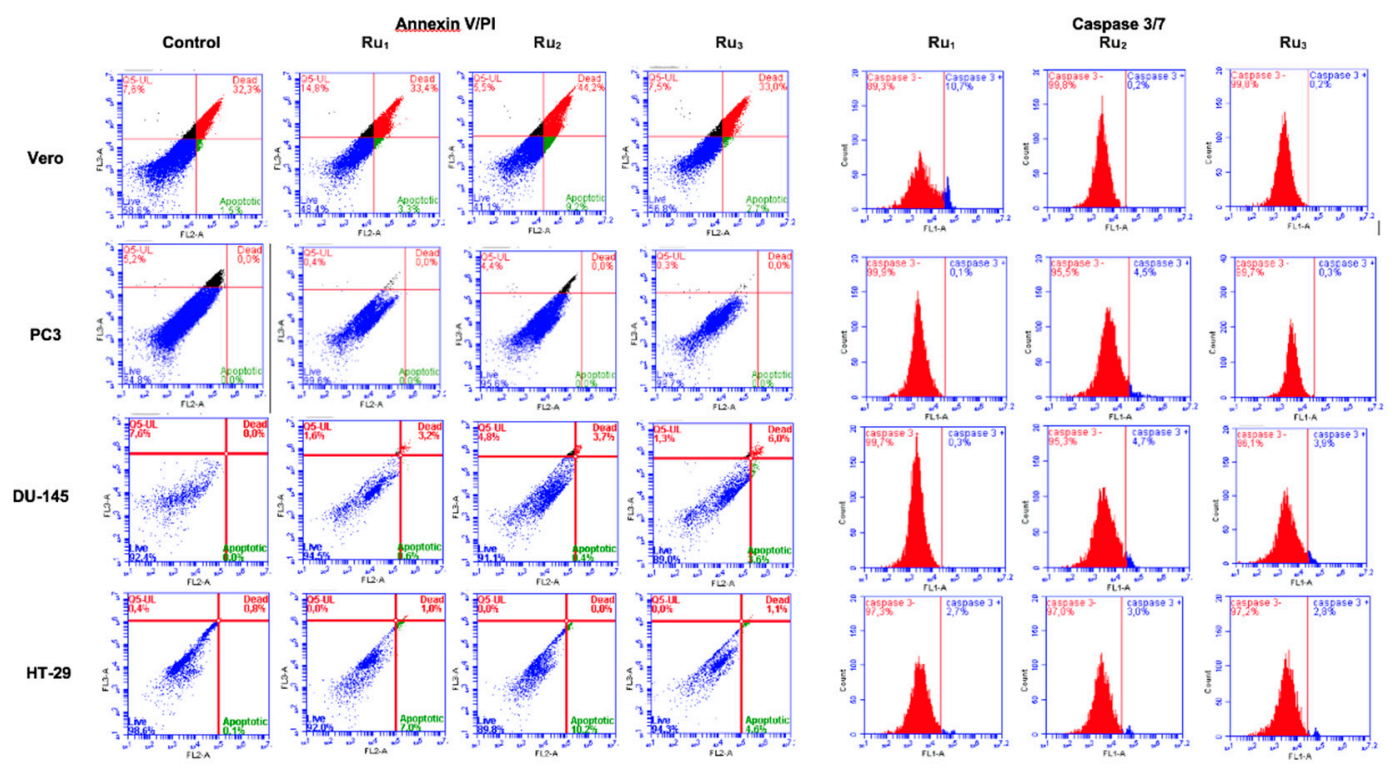

Figure 3. Representative flow cytometry dot plots show the Annexin V and Caspase 3/7 after Ru complexes incubation.

\section{Discussion}

In this study, a novel ruthenium complex was synthesized and assessed for its cellular and molecular response in different type of the cell lines. After $6 \mathbf{R u}$ complexes, three of them effective for cancer cell lines. Ru complexes incubation was triggered cellular damage and also apoptotic pathways. Therefore, to use of $\mathbf{R} \mathbf{u}$ complexes for human cancer cells may be a new treatment protocols as potent cytotoxic effect on different cancer cells (Figure 4).

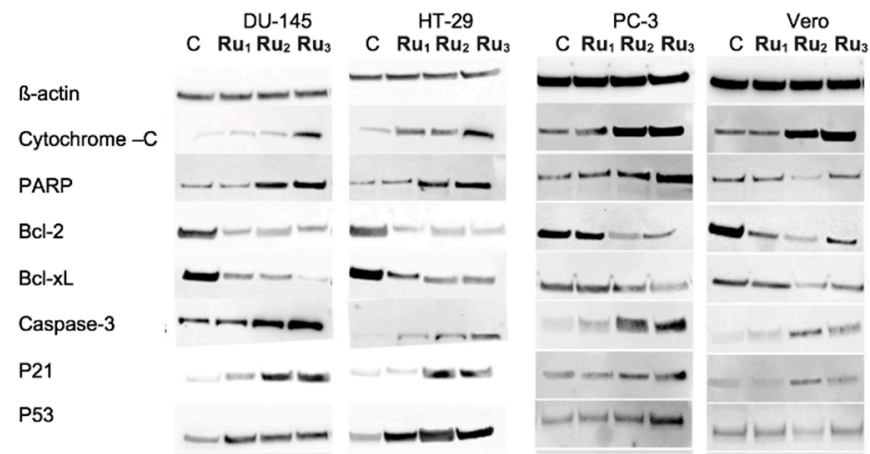

Figure 4. Immunoblot analyses in Du-145, HT-29, PC-3 and Vero cells after $48 \mathrm{~h}$ of Ru complexes incubations.

Acknowledgments: This work was supported by The Scientific and Technological Research Council of Turkey (TÜBİTAK, Project no: 214Z098).

\section{References}

1. Allardayce, C.S.; Dyson, P.J. Ruthenium in medicine: Current clinical uses and future prospect. Platinum Met. Rev. 2001, 45, 62-69.

2. Guisado-Barrios, G.; Hiller, J.; Peris, E. Pyracene-Linked Bis-Imidazolylidine Complexes of Palladium and Some Catalytic Benefits Produced by Bimetallic Catalyst. Chem. Eur. J. 2013, 19, 10405-10411.

3. Ang, W.H.; Dyson, P.J. Classical and Non-Classical Ruthenium-Based Anticancer Drugs: Towards Targeted Chemotherap. Eur. J. Inorg. Chem. 2006, 20, 4003-4018. 
4. Hotze, A.C.G.; Caspers, S.E.; de Vos, D.; Kooijman, H.; Spek, A.L.; Flamigni, A.; Bacac, M.; Sava, G.; Haasnoot, J.G.; Reedijk, J. Structure-dependent in vitro cytotoxicity of the isomeric complexes $\left[\mathrm{Ru}(\mathrm{L})_{2} \mathrm{Cl}_{2}\right]$ ( $\mathrm{L}=0$-tolylazopyridine and 4-methyl-2-phenylazopyridine) in comparison to $\left[\mathrm{Ru}(\operatorname{azpy})_{2} \mathrm{Cl}_{2}\right]$. JBIC J. Biol. Inorg. Chem. 2004, 9, 354-364.

5. Mendoza-Ferri, M.-G.; Hartinger, C.G.; Nazarov, A.A.; Kandioller, W.; Severin, K.; Keppler, B.K. Modifying the structure of dinuclear ruthenium complexes with antitumor activity. Appl. Organomet. Chem. 2008, 22, 326-332.

6. Novakova, O.; Kasparkova, J.; Vrana, O.; Vanvliet, P.M.; Reedijk, J.; Brabec, V. Correlation between Cytotoxicity and DNA-Binding of Polypyridyl Ruthenium Complexe. Biochemistry 1995, 34, 12369-12378.

7. Ohndorf, U.M.; Rould, M.A.; He, Q.; Pabo, C.O.; Lippard, S.J. Basis for Recognition of cisplatin-modified DNA by high-mobility-group proteins. Nature 1999, 399, 708-712.

8. Wong, E.; Giandomenico, C.M. Current status of platinum-based antitumor drug. Chem. Rev. 1999, 99, 2451-2465.

(C) 2018 by the authors. Licensee MDPI, Basel, Switzerland. This article is an open access article distributed under the terms and conditions of the Creative Commons Attribution (CC BY) license (http://creativecommons.org/licenses/by/4.0/). 